\title{
Debatedor
}

\section{Uma agenda necessária}

\section{A necessary agenda}

Jorge Mesquita Huet Machado

O artigo "Modelo de desenvolvimento, agrotóxicos e saúde: um panorama da realidade agrícola brasileira e propostas para uma agenda de pesquisa inovadora" representa um guia de prioridades para o enfrentamento da questão dos agrotóxicos no Brasil. É um texto necessário e instigante. É necessário dada a relevância do tema dos agrotóxicos para a saúde pública e a premência em situar o seu uso no contexto da realidade agrícola brasileira. É também instigante, pois revela um cenário que deve ser aprofundado e descortinado até seu desvendamento por completo. Daí a necessidade de uma agenda de pesquisa e de sua incorporação nos processos de promoção da saúde.

O contexto da utilização dos agrotóxicos, sua magnitude e tendência são explorados de maneira a transparecer um uso acima do racional e descontrolado. O forte apelo à utilização dos agrotóxicos e a acumulação derivada de seu uso em si são fundamentados no volume de capital envolvido na compra e venda de produtos tóxicos destinados principalmente à lavoura extensiva, monoculturas de uso intensivo de meios de capital. O que os autores estabelecem como central no artigo é como observar esse modelo para desvendar suas contradições de impactos na saúde humana, ambientais e sociais, que em médio e longo prazos implicam

${ }^{1}$ Doutor em Saúde Pública, tecnologista em Saúde Pública. Assessor da Vice-Presidência de Ambiente e Atenção e Promoção da Saúde da Fundação Oswaldo Cruz, Rio de Janeiro, RJ, Brasil. Contato: Fundação Oswaldo Cruz, Castelo Mourisco - VPAAPS. Avenida Brasil, 4365, Manguinhos, Rio de Janeiro - RJ, Brasil. CEP: 21040-900. Email: jorgemhm@fiocruz.br. 
em uma insustentabilidade sanitária, ambiental e social deste modelo.

A proposta de uma agenda de pesquisa requer, ao mesmo tempo, um programa de restrição do uso dos agrotóxicos no Brasil: a agenda do uso restrito. A título de provocação ao debate, enuncio aqui algumas propostas instigadas pela leitura do texto.

\section{Governança}

- Instituir grupo permanente de acompanhamento dessa política intersetorial, "Agenda de restrição do uso de agrotóxicos no Brasil”, sob a coordenação do Ministério da Saúde ou da comissão de saúde do Congresso Nacional.

- Identificar e mapear grupos de pesquisa e experiências que vêm contribuindo para a produção científica e metodológica em trabalho, saúde e ambiente.

- Estabelecer rede de trabalho e discussão em trabalho, saúde e ambiente.

- Reconhecer a questão química (produção, uso, impacto e controle de substâncias químicas) como um dos eixos articuladores.

- Priorizar a questão do agronegócio, da monocultura, dos transgênicos, dos agrotóxicos e do setor sucro-alcooleiro na discussão, na pesquisa e na atenção em saúde/trabalho/ambiente.

- Ampliar a participação nos fóruns estabelecidos, buscando contribuir com sua qualificação como, por exemplo, na Comissão Nacional de Segurança Química, nas Comissões Interinstitucionais de Saúde do Trabalhador e do Meio Ambiente do Conselho Nacional de Saúde (CNS), no próprio CNS e no Conselho Nacional de Meio Ambiente (Conama).

- Fortalecer relações solidárias com os diversos movimentos sociais envolvidos na questão rural, apoiando a difusão de técnicas agrícolas sustentáveis junto à Confederação dos Trabalhadores da Agricultura (Contag), aos Movimentos dos Trabalhadores sem Terra (MST), aos movimentos de povos de floresta, dos povos indígenas, dos quilombolas e dos pequenos produtores rurais.

- Estabelecer equipe técnica de coordenação dos trabalhos da comissão junto aos órgãos de execução.

- Estabelecer equipes de vigilância específica para atender ao programa de redução do uso de agrotóxico inspirada no modelo de contro- le da febre aftosa, que possui uma cobertura da vigilância de 100\% dos bois (PIGNATI; MACHADO, 2011).

\section{Vigilância em saúde}

- Colocar em prática o componente de promoção da saúde do plano de vigilância dos agrotóxicos do Ministério da Saúde (BRASIL, 2009), hoje em processo de pactuação no Sistema Único de Saúde (SUS).

- Instituir uma meta intersetorial de redução pela metade, em 3 anos, da utilização de agrotóxicos classificados como extremamente e altamente tóxicos.

- Estabelecer processo de vigilância em saúde articulado intra e intersetorialmente.

- Desencadear ações de vigilância em saúde ambiental e de saúde do trabalhador a partir dos dados do Programa de Análise de Resíduos em Agrotóxicos da Agência Nacional de Vigilância Sanitária (PARA/Anvisa) ${ }^{2}$.

- Estabelecer parâmetros decrescentes de inconformidades observadas no PARA/Anvisa.

- Adequar o uso dos agrotóxicos às lavouras prescritas.

- Fiscalizar o comércio varejista dos agrotóxicos, identificando a prescrição e associando aos usos reais.

- Estabelecer patamar de contaminação química na água potável para reduzi-lo até chegar ao indicador recomendado na União Europeia em 3 anos.

- Implementar o modelo de atenção integral à saúde das populações expostas a agrotóxicos.

- Estabelecer a vigilância em saúde do trabalhador e em saúde ambiental em todo ciclo de vida dos agrotóxicos (Figura 1).

- Fortalecer as alternativas tecnológicas ao uso de agrotóxicos, em especial as alternativas agroecológicas.

\section{Financiamento}

- Reverter os incentivos fiscais que favorecem a utilização dos agrotóxicos.

- Criar um fundo de financiamento de investigação e atividades de vigilância em saúde para redução do uso dos agrotóxicos no Brasil.

\footnotetext{
${ }^{2}$ Disponível em <http://portal.anvisa.gov.br/wps/content/Anvisa + Portal/Anvisa/Inicio/Agrotoxicos +e+Toxicologia/Assuntos + de+Interesse/ Programa+de+Analise+de+Residuos+de+Agrotoxicos+em+Alimentos >. Acesso em: 24 abr. 2012.
} 
Essas, entre outras propostas, devem ser discutidas nas agendas do SUS, especificamente pelas Vigilâncias em Saúde Ambiental e pela Rede Nacional de Atenção Integral em Saúde do Trabalhador, a Renast, dentro do componente de vigilância em saúde da Relação Nacional de Ações e Serviços de Saúde (Renases), a ser contratualizada pelos estados e municípios.

O uso dos agrotóxicos deve ser visto como uma questão de segurança química que deve se alinhar à gestão estratégica dos produtos químicos que aponta os agrotóxicos como um foco importante. É uma questão de segurança alimentar e de reprodução social que ameaça a vida no nosso planeta.

Como vemos no artigo de Porto e Soares, o dimensionamento do impacto na saúde, apesar de crescente, ainda é insuficiente e a resposta do Estado, de controle do uso de agrotóxico, é extremamente tímida.

O momento é de reflexão, aprofundamento e ação em relação ao uso dos agrotóxicos no Brasil, no sentido do desvelamento do seu real impacto na saúde pública, do grau de intoxicação dos trabalhadores rurais e de contaminação, via alimentos, de toda a população brasileira e de como pode ser revertido esse processo.

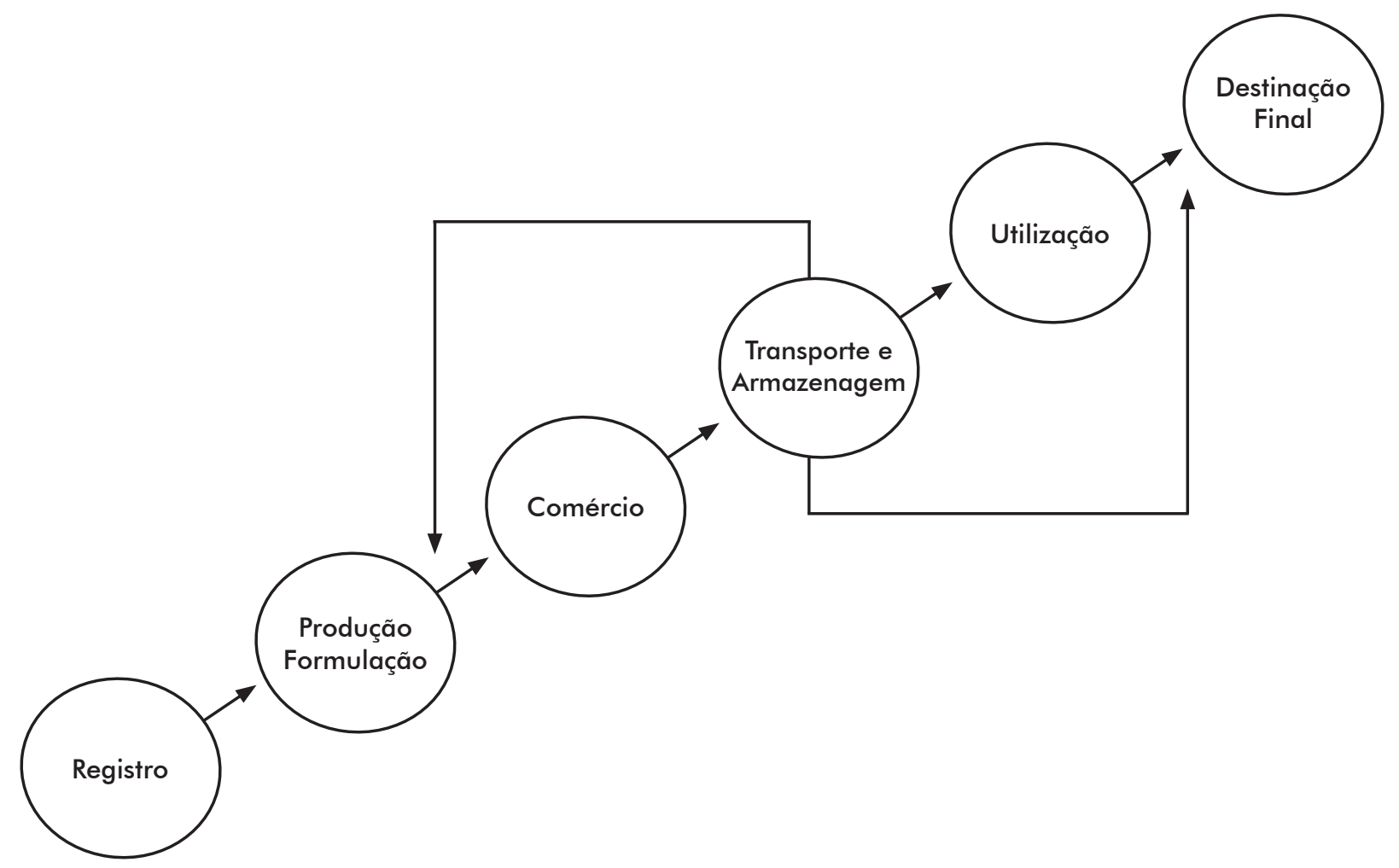

Figura 1 Ciclo de vida dos agrotóxicos

Fonte: elaborado pelo autor

\section{Referências}

BRASIL. Ministério da Saúde. Secretaria de Vigilância em Saúde. Departamento de Vigilância em Saúde Ambiental e Saúde do Trabalhador. Coordenação Geral de Vigilância em Saúde Ambiental. Plano Integrado de Vigilância em Saúde de populações Expostas aos Agrotóxicos, 2009. Disponível em: < http:/portal.saude.gov.br/portal/arquivos/ pdf/plano_agrotoxico.pdf>. Acesso em: 03 abr. 2012.
PIGNATI, W. A.; MACHADO, J. M. H. O agronegócio e seus impactos na saúde dos trabalhadores e da população do estado do Mato Grosso. In: MINAYOGOMEZ, M.; MACHADO, J. M. H.; PENA, P. G. L. Saúde do trabalhador na sociedade brasileira contemporânea. Rio de Janeiro: Fiocruz, 2011. p. 245-272.

Recebido: 16/08/2011

Aprovado: 27/04/2012 